\title{
PERBANDINGAN METODE COSINE SIMILARITY DENGAN METODE JACCARD SIMILARITY PADA APLIKASI PENCARIAN TERJEMAH AL-QUR'AN DALAM BAHASA INDONESIA
}

\author{
Ogie Nurdiana ${ }^{1}$, Jumadi $^{2}$, Dian Nursantika ${ }^{3}$ \\ 1,2,3 Jurusan Teknik Informatika, Fakultas Sains dan Teknologi \\ Universitas Islam Negeri Sunan Gunung Djati Bandung \\ J1. A.H. Nasution 105, Bandung 40614 Indonesia \\ 1ogie.nurdiana447@gmail.com,2jumadi@uinsgd.ac.id, 3dianursantika@gmail.com
}

\begin{abstract}
Todays there are more applications supporting Alqurán to facilitate such a study, which could be called digital AL-Quran. But when using applications digital AL-Quran, which has many applications users experience difficulties when searching for a word that users want. This occurs when users misspell a word you want to search and applications that are not yet able to identify or justify the wrong word. In this thesis made the information retrieval system that is used to find information that is relevant to the needs of its users automatically based on conformity to the query of a collection of information. Algoritma used to determine the similarity (degree of similarity) or relevant similarity algoritma, cosine, Jaccard, and nearest neighbor (k-nn) for comparing algoritma that are more relevant to the translation application alquran. The test result proves that the cosine similarity algoritma has the highest value with the percentage of $41 \%$ compared with Jaccard $19 \%$ algoritma and nearest neighbor (k-nn) $40 \%$ on translation of AL-Quran as much 6326 document and 33 query different experiments.
\end{abstract}

Keyword - Alqur'an, Relevan, Cosine, Jaccard, Nearest Neighbor (K-NN)

\section{PENDAHULUAN}

\section{A. Latar Belakang}

Al-Quran merupakan wahyu Allah atau kalam Ilahi yang diturunkan sebagai mukjizat kepada Nabi Muhammad SAW. Al-Quran diturunkan untuk menjadi pegangan bagi umat manusia yang ingin mencapai kebahagiaan, baik di dunia maupun di akhirat. Al-Quran mengandung nilainilai yang berhubungan dengan keimanan, syariah, akhlak serta peraturan-peraturan yang mengatur tingkah laku dan tata cara hidup manusia, baik sebagai makhluk individu maupun makhluk sosial. Al-Quran juga mengandung falsafah, kisah-kisah dan sumber ilmu pengetahuan, sebagai pelajaran, nasihat dan pencerdasan bagi umat manusia. Al-Quran dengan susunan kata yang indah, kalimat yang baik dan terang serta gaya bahasa yang mengagumkan, memberikan inspirasi yang tidak pernah kering.

Dengan kemajuan teknologi yang sangat pesat ini sudah banyak aplikasi penunjang Al-Quran untuk memudahkan untuk mempelajarinya, yang bisa disebut atau di artikan dengan adanya Al-Quran Digital. Akan tetapi, ketika menggunakan aplikasi Al-Quran Digital yang sudah banyak beredar di dunia maya, pengguna aplikasi mengalami kesulitan pada saat mencari dari sebuat kata yang pengguna inginkan dengan salah satunya yaitu dengan kesalahan pengguna dalam penulisan dari suatu kata yang dicarinya dan aplikasi pada saat ini masih kurang atau belum menangani atau membenarkan kata yang salah. Maka dilakukan perancangan dan pembuatan aplikasi yang memudahkan seseorang dalam menemmukan padanan terjemah al-qur'an, untuk mencari padanan yang sesuai dilakukan dengan mengukur kemiripan dokumen terkait (document similarity) tetapi dalam pengaplikasian banyak yang beredar penggunaan pengukuran kemiripan tanpa melihat keakuratan dari metode atau algoritma yang digunakan, pada permasalahan tersebut maka dibuatkan perbandingan untuk memilih metode yang lebih menunjang keakuratan dari pengukuran kemiripan.

\section{B. Tujuan}

Mengimplementasikan text mining menggunakan perbandingan algoritma cosine similarity dengan algoritma jaccard similarity dan metode tambahan $k$ nearest neighbor $(K-N N)$ untuk mendukung pencocokan kata yang lebih akurat dalam terjemah AlQur'an.

\section{LANDASAN TEORI}

\section{A. Text Mining}

Data mining sebagai proses untuk mendapatkan informasi yang berguna dari gudang basis data yang benar. Data mining juga dapat diartikan sebagai pengekstrakan informasi baru yang diambil dari bongkahan data besar yang 
membantu dalam pengambilan keputusan. Istilah data mining kadang disebut juga knowledge discovery.[1]

Data teks akan diproses menjadi data numerik agar dapat dilakukan proses lebih lanjut. Sehingga dalam text mining ada istilah preprocessing data, yaitu proses pendahulu yang diterapkan terhadap data teks yang bertujuan untuk menghasilkan data numerik. Pada proses preprosesing merupakan tahap dimana deskripsi di tangani untuk dapat siap diproses memasuki tahap text mining. [2] Tahap-tahap tersebut adalah :

\section{Parsing/Tokenizing}

Parsing yaitu sebuah proses yang dilakukan seseorang untuk menjadikan sebuah kalimat menjadi lebih bermakna atau berada dengan cara memecah kalimat tersebut menjadi kata-kata atau frase-frase ("Parsing").

2. Stopwords Removal/ Filtering

Stopwords removal merupakan proses penghilangan kata tidak penting pada deskripsi melalui pengecekan kata-kata hasil parsing deskripsi apakah termasuk di dalam daftar kata tidak penting (stoplist) atau tidak. Jika termasuk di dalam stoplist maka kata-kata tersebut akan diremove dari deskripsi sehingga kata-kata yang tersisa di dalam deskripsi di anggap sebagai katakata penting atau keywords.

\section{Stemming}

stemming digunakan untuk mengurangi ukuran dari suatu ukuran index file. Misalnya dalam suatu deskripsi terdapat variant kata "memberikan", "diberikan", "memberi" dan "diberi" hanya memiliki akar kata (stem) yaitu "beri". Ukuran file daftar index yang semula berjumlah lima record akan di-reduce sehingga menjadi satu record saja.

\section{Tagging}

Tahap tagging merupakan tahap mencari bentuk awal atau root dari tiap kata lampau atau kata hasil stemming yang bukan bahasa indonesia. Berikut contoh tagging dalam bahasa inggris.

\section{Anayizing}

Tahap analyzing merupakan tahap penentuan seberapa jauh keterhubungan antara kata-kata dengan dokumen yang ada.

\section{B. Pembobotan Term Frequency-Invers Document Frequency}

Tf-Idf yaitu perhitungan yang menggambarkan seberapa pentingnya kata (term) dalam sebuah dokumen. Proses ini digunakan untuk menilai bobot relevansi term dari sebuah dokumen terhadap seluruh dokumen. Term frequency adalah ukuran seringnya kemunculan sebuah term dalam sebuah dokumen. IDF merupakan banyaknya istilah tertentu dalam keseluruhan dokumen, dapat dihitung dengan persamaan (1):[3]

$$
i d f_{j=\log \frac{n}{n_{j}}}
$$

Dimana $n$ merupakan jumlah dokumen yang di gunakan, $n_{j}$ merupakan hasil $d f$ (document frequency), $\log$ digunakan untuk memperkecil pengaruhnya relative terhadap if. Bobot dari term dihitung menggunakan ukuran $t f-i d f$ dalam persamaan (2) :

$$
w=t f \mathrm{x} i d f
$$

Dimana $t f$ merupakan kemunculan term dari setiap dokumen, dan $w$ merupakan bobot dokumen terhadap kata atau bobot dari key terhadap dokumen.

\section{Cosine Siimilarity}

Metode Cosine Similarity merupakan metode yang digunakan untuk menghitung similarity (tingkat kesamaan) antar dua buah objek. Secara umum penghitungan metode ini didasarkan pada vector space similarity measure. Metode cosine similarity ini menghitung similarity antara dua buah objek (misalkan D1 dan D2) yang dinyatakan dalam dua buah vector dengan menggunakan keywords (kata kunci) dari sebuah dokumen sebagai ukuran. [4]

$$
\operatorname{CosSim}\left(d_{i}, q_{i}\right)=\frac{q_{i} \cdot d_{i}}{\left|q_{i}\right|\left|d_{i}\right|}=\frac{\sum_{j=1}^{t}\left(q_{i j} \cdot d_{i j}\right)}{\sqrt{\sum_{j=1}^{t}\left(q_{i j}\right)^{2} \cdot \sum_{j=1}^{t}\left(d_{i j}\right)^{2}}}
$$

Keterangan :

$q_{i j}=$ bobot istilah $j$ pada dokumen $i=t f_{i j} . i d f_{j}$

$d_{i j}=$ bobot istilah $j$ pada dokumen $i=t f_{i j} . i d f_{j}$

\section{Jaccard Similarity}

Jaccard Coeficient adalah salah satu metode yang dipakai untuk menghitung similarity antara dua objects (items). Seperti halnya cosine distance dan matching coefficient, secara umum perhitungan metode ini didasarkan pada vector space similarity measure.[5]

$$
\mathbf{J}(\mathrm{X}, \mathrm{Y})=\frac{\sum_{i=1}^{p} x_{i} y_{i}}{\sum_{j=1}^{p} x_{i}{ }^{2}+\sum_{j=1}^{p} y_{i}{ }^{2}-\sum_{i=1}^{p} x_{i} y_{i}}
$$

Dimana $\mathrm{x}$ merupakan nilai dari key dan y nilai dari dokumen.

\section{E. $K$-NN (K-Nearest Neighbor)}

$K$-Nearest Neighbor merupakan sebuah algoritma yang sering digunakan untuk klasifikasi teks dan data. Penggunaan K-Nearest Neighbor mempunyai sifat selflearning dimana jika semakin banyak dokumen, maka makin banyak pula sumber yang dapat digunakan untuk dibandingkan. $K$ Nearest Neighbor berarti mencari tetangga yang paling dekat dengan sets yang akan di klasifikasi.[6]

$$
D_{e u c}(P, Q)=\sqrt{\sum_{i=1}^{n}\left(p_{i}-q_{i}\right)^{2}}
$$

Keterangan :

$P$ dan $Q=$ titik pada ruang vector $n$-dimensi. $p_{i}$ dan $q_{i}=$ besaran scalar untuk dimensi ke- $i$ dalam ruang vector $n$-dimensi

Untuk mengukur jarak antara $p_{i}$ dan $q_{i}$ maka di lakukan nilai 1 untuk nilai maksimum karena akar kuadrat jika jarak biasanya lebih besar dari 1, dan jika jarak kurang dari 1 akan menghasilkan nilai yang sangat penting untuk similarity, maka rumusnya :

$$
D_{\text {euc }}(P, Q)=\frac{1}{1+\sqrt{\sum_{i=1}^{n}\left(p_{i}-q_{i}\right)^{2}}}
$$




\section{ANALISIS DAN PERANCANGAN}

\section{A. Analisis}

Analisis kebutuhan yaitu tahapan untuk mengidentifikasi permasalahan serta proses yang terjadi dalam membangun sebuah sistem. Analisis dilakukan terhadap kebutuhan website yang akan dibangun, agar permanfaatan website yang digunakan memperoleh hasil yang optimal. Kemudian dilakukan analisis terhadap pengguna website, yang digunakan sebagai pembagian otoritas penggunaan website. Pada analisis kebutuhan bertujuan untuk mengidentifikasi jalannya suatu sistem dan permasalahanpermasalahan yang terjadi pada sistem yang dibuat.

\section{B. Perancangan Sistem}

Dalam pembahasan perancangan sistem akan menjelaskan tentang perancangan sistem. Penelitian aplikasi yang dirancang yaitu aplikasi berbasis web yang terdiri dari administrator yang berperan untuk mengelola aplikasi meliputi data sepenuhnya dan user yang berperan untuk melakukan pencarian berkaitan informasi.

\section{Use Case Diagram}

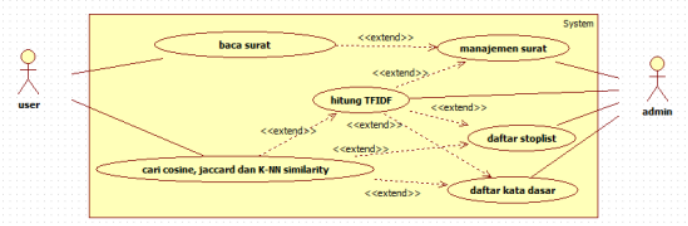

Gambar 3.1 Use Case Diagram

Dalam representasi Gambar 3.1 terdapat dua actor yakni administrator dan user. Administrator berperan sebagai pengelola utama dari aplikasi yang dapat mengakses semua fasilitas yang ada dalam aplikasi. Sedangkan user adalah pengguna secara umum dari membaca surat Al-Qur'an dan melakukan proses pencarian terjemah.

2. Skema Aplikasi

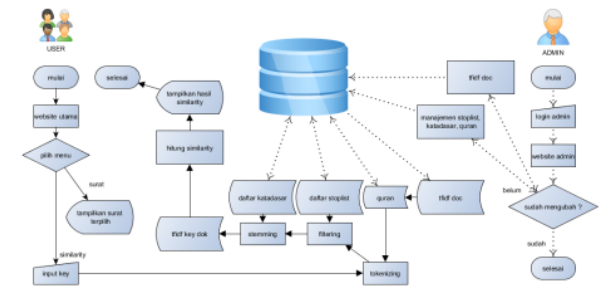

Gambar 3.2 Skema Aplikasi

Skema proses aplikasi terdapat 2 pengguna yaitu user dan admin, admin bisa melakukan manajemen dan penghitungan tfidf akan tetapi terdapat pemilihan setelah login admin yaitu pemilihan apakah admin akan mengedit atau sudah memenej, apabila sudah maka proses admin akan selesai, jika belum maka ada pemilihan untuk memenej atau penghitungan $t$ fidf, alur dari tfidf admin yaitu proses yang dilakukan di database berupa data dari quran dan di proses text mining yang terdiri dari tokenizing, filtering dan stemming dari data yang sudah ada di database, apabila admin memilih menejemen yang terdiri daftar stoplist, daftar kata dasar dan data quran akan otomatis terpanggil di database ketika pemilihan berlangsung. Pada proses user terdapat 2 pemilihan yaitu surat untuk melihat data quran dan similarity untuk menghitung kemiripan yang di awali dengan input key dan di proses ke tahap text mining dan menghitung keiripan dengan metode yang digunakan.

3. Arsitektur Sistem

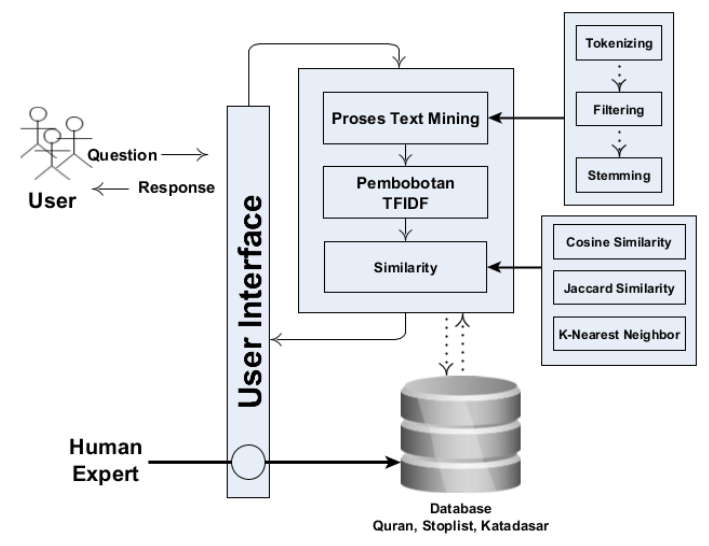

Gambar 3.3 Arsitektur Sistem

Pada Gambar 3.3 sistem aplikasi terdapat 2 pengguna yaitu user dan human expert atau admin, human expert bisa melakukan apapun yang berada di database, sedangkan user dari input pertanyaan akan menghasilkan hasil akhir dari pertanyaan itu dengan proses text mining kemudian pembobotan tfidf dan penghitungan kemiripan atau similarity dengan metode yang di gunakan.

\section{IMPLEMENTASI DAN PENGUJIAN}

\section{A. Implementasi}

\section{Implementasi User Interface}

Pada tampilan menu utama user terdapat dari 2 menu yaitu browse surat yaitu menu utama user dan menu search cosine jaccard $k$ nearest neighbor $(K-N N)$ similarity merupakn menu input key.

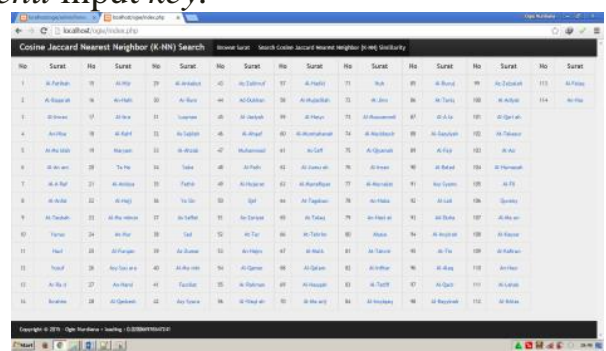

Gambar 4.1 User Interface

\section{Implementasi Admin Interface}

Halaman utama admin terdapat 3 menu yaitu browse surat merupakan tampilan utama admin, menu hitung tfidf merupakan halaman proses penghitungan tfidf seluruh dokumen, dan menu logout merupakan proses keluar akses sebagai admin 


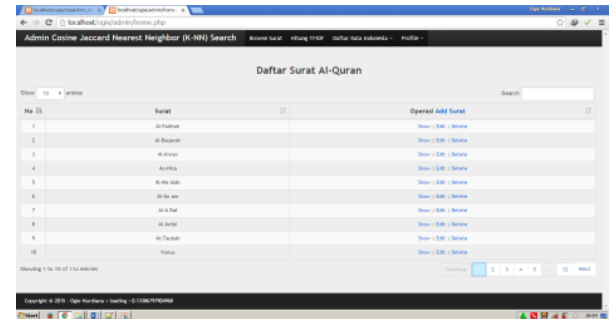

Gambar 4.2 Admin Interface

3. Pengujian

Dari hasil uji coba penghitungan probabilitas atau kemunculan dan menghitung kemiripan dokumen text dari algoritma cosine similarity, jaccard dan nearest neighbor ( $K$ $N N)$ similarity dari seluruh dokumen Al-Quran yaitu 6236 dokumen dengan pengujian dilakukan 30 kali dengan key yang berbeda. Maka hasil persentasi dan hasil rata-rata dari pengujian tersebut yaitu :

Tabel 4.1 Hasil Pengujian

\begin{tabular}{|c|c|c|c|}
\hline Kode & Cosine & Jaccard & KNN \\
\hline K1 & 0,139872 & 0,06099 & 0,095979 \\
\hline K2 & 0,02405 & 0,010935 & 0,128219 \\
\hline K3 & 0,061694 & 0,028895 & 0,125886 \\
\hline K4 & 0,133569 & 0,055498 & 0,105569 \\
\hline K5 & 0,081169 & 0,03594 & 0,119472 \\
\hline K6 & 0,070034 & 0,03223 & 0,112465 \\
\hline K7 & 0,277538 & 0,146228 & 0,062198 \\
\hline K8 & 0,295603 & 0,145796 & 0,090548 \\
\hline K9 & 0,148879 & 0,06319 & 0,056636 \\
\hline K10 & 0,198596 & 0,086176 & 0,073927 \\
\hline K11 & 0,140768 & 0,059974 & 0,101357 \\
\hline K12 & 0,103904 & 0,050617 & 0,141535 \\
\hline K13 & 0,206611 & 0,104605 & 0,108184 \\
\hline K14 & 0,103681 & 0,052328 & 0,139716 \\
\hline K15 & 0,332589 & 0,148003 & 0,117515 \\
\hline K16 & 0,203543 & 0,071302 & 0,066478 \\
\hline K17 & 0,116736 & 0,040292 & 0,08266 \\
\hline K18 & 0,14797 & 0,072231 & 0,130688 \\
\hline K19 & 0,064945 & 0,030819 & 0,147392 \\
\hline K20 & 0,094797 & 0,043095 & 0,143484 \\
\hline K21 & 0,205474 & 0,074278 & 0,066845 \\
\hline K22 & 0,057496 & 0,026982 & 0,128787 \\
\hline K23 & 0,114819 & 0,053021 & 0,147111 \\
\hline K24 & 0,202506 & 0,074082 & 0,04579 \\
\hline K25 & 0,241771 & 0,097114 & 0,08082 \\
\hline K26 & 0,090073 & 0,035277 & 0,085085 \\
\hline K27 & 0,188607 & 0,094438 & 0,095274 \\
\hline K28 & 0,238873 & 0,103154 & 0,035005 \\
\hline K29 & 0,1786 & 0,079652 & 0,103013 \\
\hline K30 & 0,084209 & 0,039216 & 0,13612 \\
\hline K31 & 0 & 0 & 0 \\
\hline K32 & 0,127077 & 0,057255 & 0,073326 \\
\hline K33 & 0 & 0 & 0 \\
\hline
\end{tabular}

Dari hasil setiap uji coba dengan 33 percobaan keyword yang berbeda maka di dapat hasil perbandingan dari setiap metode yang di gunakan, untuk mendapatkan hasil perbandingan yang di lakukan dalam persentase maka pada setiap metode harus di dapatkan hasil rata-rata terlebih dahulu. Kemudian dilakukan penghitungan hasil persentase dari setiap metode. Hasil perbandingan dari setiap metode terdapat pada Tabel 4.2

Tabel 4.46 Hasil Perbandingan

\begin{tabular}{|l|c|c|c|}
\hline & Cosine & Jaccard & KNN \\
\hline Rata-rata & 0,141699 & 0,062837 & 095366 \\
\hline Persentase & $47 \%$ & $21 \%$ & $32 \%$ \\
\hline
\end{tabular}

\section{A. Kesimpulan}

Berdasarkan Hasil Pengujian yang telah dilakukan didapat beberapa kesimpulan :

1. Metode cosine, jaccard dan k-nearest neighbor $(K-N N)$ yang digunakan pada proses klasifikasi dokumen teks dengan hasil akhir dari percobaan 33 kali dengan key yang berbeda dan total 6326 dokumen di dapat metode cosine yang nilai kemiripannya tertinggi yaitu $41 \%$ dari metode jaccard $19 \%$ dan k-nearest neighbor $(K-N N)$ $40 \%$, karena metode cosine similarity mempunyai konsep normalisasi panjang vektor data dengan membandingkan $N$-gram yang sejajar satu sama lain dari 2 pembanding. Sedangkan pada metode jaccard hanya membandingkan isi $N$-gram dengan eksak dan hanya melihat apakah ada suatu $N$-gram tertentu pada pembanding tanpa melihat posisi penulisan yang berbeda. Pada euclidean distance yang diterapkan di metode $k$-nearest neighbor ( $K$ $N N)$ tidak mempunyai konsep normalisasi panjang vektor data, sehingga nilai akurasi metode dipengaruhi oleh panjang 2 data pembanding dan harus menentukan nilai dari pamameter $K$ (jumlah dari tetangga terdekat). Maka metode cosine similarity menjadi usulan alternatif untuk mencari kemiripan dari teks mining.

2. Keakuratan hasil yang dicari sangat berpengaruh pada kata kunci yang di cari, agar hasil yang ingin dicari lebih relevan maka kata kunci harus sesuai dengan aturan penulisan bahasa Indonesia.

3. Keakuratan pengelompokan dokumen teks dan pemilihan kata untuk dijadikan sebagai term sangat terpengaruh oleh kelengkapan daftar stoplist dan hasil root kata dari stemming untuk teks bahasa Indonesia.

\section{B. Saran}

Hasil dari proyek akhir ini belumlah sempurna, untuk meningkatkan hasil yang dicapai dapat dilakukan :

1. Penambahan metode yang biasa digunakan untuk jenis teks mining seperti metode Inner Similarity dan Dice Similarity

2. Untuk penelitian selanjutnya disarankan untuk perbaikan dalam pengindeksan seluruh 
dokumen sehingga dalam pemrosesan Term Frequency-Invers Document Frequency (TF$I D F$ ) tidak memakan waktu lama.

\section{DAFTAR PUSTAKA}

[1]E. Prasetyo, Data Mining - Konsep Dan Aplikasi Manggunakan Maltab. Yogyakarta : ANDI, 2012.

[2] S. Nurhayati, "Text Mining", Implementasi Text Mining Untuk Klasifikasi Kesenian Tradisional Dengan Metode Nbc (Nä̈ve Bayes Classifier), Fakultas Teknik dan Ilmu Komputer Universitas Komputer Indonrsia. Bandung, 2010, pp. 1-5.

[3] M. Fitri, Kombinasi Tf-Idf, Perancangan Sistem Temu Balik Informasi Dengan Metode Pembobotan Kombinasi Tf-Idf Untuk Pencarian Dokumen Berbahasa Indonesia, Tanjungpura, 2013, pp. 1-6

[4] G. A. Pradnyana dan N. A. Sanjaya, "Cosine Similarity", Perancangan Dan Implementasi Automated Document Integration Dengan Menggunakan Algoritma Complete Linkage Agglomerative Hierarchical Clustering, vol. 5, (2), pp. 1-10, September 2012.

[5] S. S. S. Purwandari, Rancang Bangun Search Engine Tafsir Al-Quran Yang Mampu Memproses Teks Bahasa Indonesia Menggunakan Metode Jaccard Similarity, Fakultas Sains dan Teknologi Universitas Islam Negeri Maulana Malik Ibrahim Malang, 2012, pp. 9-27.

[6] N. Krisandi, Helmi, dan B. Prihandono, "Klasifikasi Data", Algoritma K-Nearest Neighbor Dalam Klasifikasi Data Hasil Produksi Kelapa Sawit Pada PT.Minamas Kecamatan Parindu, vol. 2, (1), pp. 33-38, 2013. 